\title{
Employee Motivation: A Leadership Imperative
}

\author{
Joshua D. Jensen $^{1}$ \\ ${ }^{1}$ Northwest Nazarene University, United States \\ Correspondence: Joshua D. Jensen, Northwest Nazarene University, United States.
}

Received: February 14, 2018

Accepted: February 28, $2018 \quad$ Online Published: March 2, 2018

doi:10.5430/ijba.v9n2p93

URL: https://doi.org/10.5430/ijba.v9n2p93

\begin{abstract}
Employee motivation is a topic that has been studied for nearly a century. Beginning with the Hawthorne Studies in the 1920s and continuing to the current day, researchers have explored the elusive phenomenon of employee motivation. Furthermore, researchers have attempted to understand how leaders can effectively lead their employees in a way that motivates them to reach their full potential. While employee motivation has been, and continues to be, the focus of much research among the social and behavioral sciences on an international scale, leaders today are in need of practical tools that can help them motivate employees more effectively. This paper provides a survey of some of the key research on employee motivation and highlights the important role that leaders play in motivating their employees to achieve high performance. Also included are some practical tools that leaders can implement to increase employee motivation.
\end{abstract}

Keywords: human resource management, employee motivation, employee engagement, organizational leadership, management

\section{Introduction}

Employee motivation has been the focus of numerous research studies over the years. The essence of how to motivate employees is still, to this day, a focal point of organizational behavior experts, business scholars, and leaders alike. According to Robbins and DeCenzo (2007), motivation is "The willingness to do something conditioned upon the action's ability to satisfy some need for the individual" (p. 217). Therefore, to motivate employees, leaders must identify the needs employees seek to satisfy, and focus their talents in ways that will help them achieve this satisfaction.

\section{Literature Review}

The study of employee motivation traces back as far as the Hawthorne Studies of 1924. In 1924, Western Electric Company conducted a series of studies at their Hawthorn Works plant outside of Chicago (Sonnenfeld, 1985). The initial studies aimed to determine the relation of the lighting in the plant to production output. The research concluded that lighting was only a minor factor in the study of output (1985). However, Elton Mayo and a few others redefined the research to examine the physical factors that cause fatigue and monotony (1985). These studies resulted in a surprising outcome. "As the conditions of work were progressively relaxed, production steadily rose, and when the original, more demanding work conditions were reintroduced, the workers' productivity dropped only slightly" (1985, p. 112). The research also reported reduced absenteeism during the study (1985).

Following these studies, several other research studies ensued to confirm previous findings. Overall, these studies continued until 1933 (Sonnenfeld, 1985). In the end, significant contributions were made to the field of organizational behavior. "It was concluded that the chief result had been to demonstrate the importance of employee attitudes and pre-occupations. The friendlier, more participative style of supervision and the freedom from tight quotas and harsh discipline, seemed to correspond with increases in both morale and in productivity" (1985, p. 113). Moreover, these research studies found the significance of social stratification between different jobholders, which prompted a closer look at the status distinction and the social relations in the work setting (1985).

This research also resulted in new observations regarding the workplace setting. "An unanticipated worker culture was revealed through group norms and activities such as the restriction of output, informal leadership patterns, friendships, job trading, cooperation, and group discipline" (1985, p. 114). This research was monumental to the field of organizational behavior. Topics related to the above such as organizational culture, status and power, formal and informal organization, job sharing, teamwork, and empowerment are all areas of focus in organizational 
behavior today. Therefore, the studies conducted between 1924 and 1933 set the foundation for the continued study of employee motivation as it relates to organizational behavior.

\subsection{Employee Motivation in the Public Sector vs. the Private Sector}

Since the initial studies of the 1920s and 1930s, there have been numerous studies on employee motivation. Many of these studies have focused on comparing and contrasting motivation in the public sector and the private sector. General perception is that public employees enjoy salaries based on longevity regardless of performance, as well as generous fringe benefit packages, while private sector employees have limitless income potential if they work hard and aim straight for the top of the organization. Following is an analysis of some of these research studies, and a discussion on their implications for employee motivation.

Philip Crewson (1997) conducted a research study on public service motivation. Research from the early 1960s showed that the reward motivations of public employees are not representative of the general workforce. Therefore, Crewson set out to investigate public employee motivation, and determine what differences exist between motivation of public sector employees and private sector employees.

Crewson's (1997) study included a comprehensive review of several past studies of public and private sector employee motivation. In short, Crewson's study confirmed several findings. First, Crewson found that public employees place greater value on helping others and being useful to society than do those in the private sector. In turn, Crewson found that private sector employees place greater value on promotions and job security. Of most significance, Crewson reports, "Although there is no significant difference between sectors in the importance placed on high pay, public employees rate other extrinsic rewards lower in importance than do employees from the private sector. In turn, intrinsic rewards are more important to public employees than to those employed in the private sector" (1997, p. 503).

Further studies support the fact that findings related to public and private sector employee motivation extend internationally. Bullock, Stritch, and Rainey (2015) surveyed public and private sector employees across 30 countries to determine employee motivation factors. The results of the study indicated that public employees held more concern for the social impact of their job as a major motivational factor. "We find evidence that public sector workers are less motivated by monetary gain than their private sector counterparts" (2015, p. 486). Similar to Crewson's (1997) findings, Bullock, Stritch, and Rainey indicated that public employees are motivated more by the meaning of the work rather than remuneration.

\subsection{Intrinsic vs. Extrinsic Motivation}

There are two basic types of motivation: intrinsic motivation and extrinsic motivation. Newstrom and Davis (2002) discussed the difference between intrinsic and extrinsic motivators. "Intrinsic motivators are internal rewards that a person feels when performing a job, so there is a direct and often immediate connection between work and rewards" (2002, p. 109). This type of motivation usually leads to an employee becoming self-motivated or energized from within to perform their best and make a valuable contribution to the organization or society.

Extrinsic motivators are different than intrinsic motivators. "Extrinsic motivators are external rewards that occur apart from the nature of work, providing no direct satisfaction at the time the work is performed" (Newstrom and Davis, 2002, p. 109). Examples of extrinsic motivators include salary increases, fringe benefits, and leave time. Although employees value these types of extrinsic rewards, Newstrom and Davis suggested that they are not effective motivators. However, according to research by Crewson (1997), extrinsic motivators do have an impact on employee motivation, particularly in the private sector.

\subsection{Organizational Commitment}

Crewson's (1997) study led to another significant finding. It is clear from the research that employee motivation is directly linked to organizational commitment. "Organizational commitment is defined in terms of the strength of an individual's identification with and involvement in a particular organization" (1997, p. 507). Crewson argues that organizational commitment is a combination of three distinct factors: a strong belief and acceptance of the organization's goals and values, eagerness to work hard for the organization, and a desire to remain a member of the organization. This strongly suggests that organizational commitment serves as a better predictor of employee behavior than other attitudinal measures, such as job satisfaction.

Jurkiewicz, Massey, and Brown (1998) conducted a comparative study on motivation in public and private organizations. Jurkiewicz et al. argued that motivation is a primary task for managers. "It is said that $10 \%$ of a manager's time is spent on developing motivational tactics" (1998, p. 230). It is generally agreed that if managers 
can accurately determine what motivates their employees, the more effective they will be at maximizing productivity and enhancing performance.

Jurkiewicz et al. referenced a study of private sector motivation performed by Kovach in 1995. This longitudinal study spanned 50 years and yielded interesting results. The study revealed that managers in 1995 varied little from managers in 1946 in regards to what they thought motivated their employees (1998). However, whereas managers' assessment of these motivators remained unchanged for 50 years, employees' assessments changed drastically from 1946 to 1995 . "The results of this study of 1,000 employees and their managers reveals a startling disparity between what managers believe motivates their employees and what really motivates them" (1998, p. 231).

This finding is surprising, considering that the private sector has implemented costly compensation and incentive programs built around these misconceptions of what motivates employees. This finding caused Jurkiewicz et al. to conduct further research on employee motivation in both the private and public sectors. To that end, Jurkiewicz et al. conducted surveys of both public and private sector employees and managers to ascertain the perceptions of motivational factors of each group as well as in both sectors.

"The results of this study suggest that, collectively, public employees are significantly different from their private-sector counterparts with respect to the motivational attributes of the job" (Jurkiewicz et al., 1998, p. 235). The results showed that public sector employees ranked "a stable and secure future" first, while private sector employees ranked "high salary" first. Furthermore, the results revealed that public sector employees ranked "high prestige and social status" last, while private-sector counterparts ranked "freedom from supervision" last.

Continuing, Jurkiewicz et al. (1998) discussed the recent popularity of crossover employment-those who have experience in one sector choosing to switch employment to the other sector. Jurkiewicz et al. presumed that this sudden occurrence of crossover employment was driven by the public sector employees' desire for higher pay and the private sector employees' desire for worthwhile service to society. Jurkiewicz et al. went one-step further and suggested that crossover employment may be a significant factor in the recent deterioration of public trust in government. Jurkiewicz et al. further argued that this leads to other issues with further consequences. "One of the key issues arising here is the blurring of the sectors, a concern historically more volatile in the public sector than the private sector, with some of the latest iterations debating the demand for, or scourge of, public entrepreneurship" (1998, p. 246).

Jurkiewicz et al. (1998) discussed the implications of their research findings. The researchers noted that each of the private organizations that participated in the study had implemented team-building, quality circle, and reengineering type of training programs. Jurkiewicz et al. considered that these programs may have had a significant effect on the culture of the organization, at a minimum emphasizing a concern for how one's behavior affects others in the workplace (1998). Contrastingly, Jurkiewicz et al. reported that none of the public sector organizations that participated in the study were engaged in systematic training programs (1998). This raises questions and suggestions for further research as to the effect of such training programs on employee satisfaction and motivation (1998).

Moon (2000) agreed with Crewson (1997) regarding the impact of organizational commitment on employee motivation. Moon posited that employee motivation directly relates to organizational commitment. Moon conducted a study regarding organizational commitment in new public management (NPM). "The NPM movement has emphasized the value of market efficiency in the public sector and stimulated various managerial reinventions at the federal, state, and the local level" (2000, p. 177). Consequently, NPM has duplicated many private sector philosophies and methodologies in the public sector. Moon set out to investigate organizational commitment and employee motivation within the framework of the NPM movement.

For example, the idea of pay-for-performance, a compensation philosophy invented in the private sector, has now been adopted by many public agencies as a means of enhancing motivation and improving organizational performance (Moon, 2000). However, as previous studies have indicated, motivators for public employees are much different than motivators for private sector employees (Crewson, 1997; Jurkiewicz, Massey \& Brown, 1998; Moon, 2000). Specifically, pay-for-performance is an extrinsic motivator. Research suggests that private sector employees tend to be motivated by extrinsic factors. Therefore, pay-for-performance is likely an effective motivator for private sector employees. However, research also suggests that public employees tend to be motivated intrinsically. Therefore, a pay-for-performance system, although effective as it may be in the private sector, most likely is not a motivator for public employees (Moon, 2000).

Moon's (2000) research suggests a strong connection between organizational commitment and employee motivation. "Those who have a higher level of intrinsic motivation are likely to have a higher level of organizational 
commitment" (2000, p. 184). Therefore, Moon argued that organizational commitment is stronger in the public sector than in the private sector. Furthermore, Moon's research concluded, similarly to others, that public employees tend to be more intrinsically motivated while private sector employees are motivated by extrinsic factors.

Further studies have explored the relationship between organizational commitment and employee motivation from an international perspective (Bullock, Stritch, \& Rainey, 2015; Gagne et al., 2014; Cerase \& Farinella, 2009). In a study of employees across 30 countries, Bullock, Stritch, \& Rainey found that organizational commitment varied between public and private employees. Specifically, in the majority of countries studied, public employees experienced higher levels of organizational commitment than their private sector counterparts. "In 22 of the 30 countries, government workers report higher levels of organizational commitment than private sector workers" (p. 484). Furthermore, Cerase \& Farinella (2009) as well as Gagne et al. (2014) explored the relationship between employee motivation and organizational commitment, with findings that affirm the positive relationship between these two phenomena.

\subsection{Organizational Culture}

Recent research by McGregor and Doshi (2015) further refined employee motivation by examining how organizational culture drives performance. They began by looking at the main reasons why people work. Adapted from previous research by Deci and Ryan (1985), McGregor and Doshi identify six main reasons why people work: play, purpose, potential, emotional pressure, economic pressure, and inertia. "The work of many researcher has found that the first three motives tend to increase performance, while the latter three hurt it" $(2015, \mathrm{p}$. 3). Companies with strong organizational cultures are ones that focus on the first three motives and work to embed them into the cultural fiber of the organization.

"Play is when you are motivated by the work itself. You work because you enjoy it" (McGregor \& Doshi, 2015, p. 3). Play is highlighted by a love for the work, opportunities to have a say in how the work is completed, and the opportunity to experiment and address challenges. "Purpose is when the direct outcome of the work fits your identity. You work because you value the work's impact" (McGregor \& Doshi, 2015, p. 3). When a person's values align with an organization's values, they feel a sense of purpose and likely experience enhanced performance and organizational commitment. "Potential is when the outcome of the work benefits your identity. In other words, the work enhances your potential" (McGregor \& Doshi, 2015, p. 3). Enhanced motivation results from the ability to grow within an organization and experienced increased levels of responsibility and a clear career path.

\section{Leadership and Employee Motivation}

Research has revealed much about the determinants of employee motivation, yet leaders continue to struggle with motivating employees. How can leaders effectively motivate their employees? The answer is quite elusive, as humans are fickle creatures with a vast array of wants and needs that change and evolve over time. However, if leaders are intentional in their efforts to engage employees, they can succeed at increasing employee motivation. Here are a couple of recommendations.

First, leaders must know their employees intimately in order to determine their wants and needs. Leaders must engage employees at work and be intentional about making time to get to know each employee. This includes taking an interest in employees outside of the office (Tracy, 2017). Leaders need to create touchpoints with employees on a weekly basis. Ideally, leaders would have a daily touchpoint with each employee. The idea is to maintain an open line of two-way communication with each employee. This does not necessarily need to occur face-to-face on a daily basis, but can include other forms of communication. "Managers who use a combination of face-to-face, phone, and electronic communication are the most successful in engaging employees" (Harter \& Adkins, 2015, para. 6). A weekly one-on-one meeting with each employee is a great way to facilitate face-to-face touchpoints.

One-on-one meetings between leaders and employees can be highly effective if done well. To do one-on-one meetings well, leaders need to be consistent and be intentional about how they use this time. Leaders who continually schedule and then cancel one-on-one meetings send a message to the employee that the meetings are not important...or even worse, that the employee is not important. Therefore, leaders must have a schedule and stick to it (Hedges, 2013). Another key aspect of doing one-on-one meetings well is for leaders to be fully present. There is no argument that leaders are extremely busy and are balancing more responsibilities than ever before. However, leaders must be physically, mentally, and emotionally present during one-on-one meetings. "Giving someone our full, uninterrupted presence is a gift that makes a big impact" (Hedges, 2013, para. 10).

Furthermore, leaders must ensure that one-on-one meeting time effectively adds value to the employee and to the organization. It is easy for one-on-one meetings to turn into loose, unfocused discussions that lack purpose and result in no meaningful outcome. These meetings take up a considerable amount of real estate on a leader's calendar, and 
therefore should promote leader-employee intimacy, employee development, and achievement of organizational goals. One way to ensure one-on-one meetings stay focuses is to prepare discussion points. While mutual agreement on an agenda in advance for one-on-one meetings is not necessary, having a list of points that the leader would like to discuss can help keep the conversation focused. Likewise, leaders should encourage the employee to bring some discussion points to the meeting as well. "In other words, you need some structure but not too much" (Knight, 2016, para. 4).

Through these regular one-on-one meetings, as well as other regular and frequent touchpoints, leaders can get to know and understand their employees on a deeper level. Just like in any relationship, the more time people spend together, the more they get to know each other. Here, leaders develop trust and truly get to know their employees and what drives them; they learn what causes them to do what they do. In doing so, leaders engender loyalty which serves as a great motivator for the employee.

\section{Conclusion}

Employee motivation continues to be a challenge for leaders globally. Although the research on what motivates employees is clear, we must remember that these are generalizations. Leaders in organizations have the responsibility of determining what motivates each individual employee, as each one may be motivated by something completely different. Through regular touchpoints, leaders must spend time building relationships and getting to know their employees on an intimate level to determine what motivates them. For some it could be flexible schedules for family issues; for others it could be higher pay. For some it could be very clear processes and procedures to follow, and others it could be the ability to invent their own way of doing things. In the end, it all boils down to knowing your employees and engaging them in a meaningful way that will lead them to be motivated and satisfied with their work.

\section{References}

Bullock, J.B., Stritch, J.M., \& Rainey, H.G. (2015, May). International comparison of public and private employees' work motives, attitudes, and perceived rewards. Public Administration Review, 75(3), 479-489. https://doi.org/10.1111/puar.12356

Cerase, F.P., \& Farinella, D. (2009, June). Public service motivation: How does it relate to management reforms and changes in the working situation of public organizations? A case study pf the Italian Revenue Agency. Public Policy and Administration, 24(3), 281-308. https://doi.org/10.1177/0952076709103812

Crewson, P.E. (1997, October). Public-service motivation: Building empirical evidence of incidence and effect. Journal of Public Administration Research and Theory, 7(4), 499-518. https://doi.org/10.1093/oxfordjournals.jpart.a024363

Gagne, M., Forest, J., Vansteenkiste, M., Crevier-Braud, L., van den Broeck, A., Aspeli, A., ... Westbye, C. (2014, February). The Multidimensional Work Motivation Scale: Validation evidence in seven languages and nine countries. European Journal of Work and Organizational Psychology, 24(2), 178-196. https://doi.org/10.1080/1359432X.2013.877892

Harter, J. \& Askins, A. (2015, April). What great managers do to engage employees. Harvard Business Review. Retrieved from https://hbr.org/2015/04/what-great-managers-do-to-engage-employees

Hedges, K. (2013). The secret to effective one-on-one meetings with direct reports. Forbes, November 11. Retrieved from

https://www.forbes.com/sites/work-in-progress/2013/11/11/the-secret-to-effective-one-on-one-meetings-with-di rect-reports/\#22a8829b4687

Jurkiewicz, C.L., Massey, T.K., \& Brown, R.G. (1998, March). Motivation in public and private organizations: A comparative study. Public Productivity \& Management Review, 21(3), 230-250. https://doi.org/10.2307/3380856

Knight, R. (2016, August 8). How to make your one-on-ones with employees more productive. Harvard Business Review.

from https://hbr.org/2016/08/how-to-make-your-one-on-ones-with-employees-more-productive

McGregor, L., \& Doshi, N. (2015, November 25). How company culture shapes employee motivation. Harvard Business Review. Retrieved from https://hbr.org/2015/11/how-company-culture-shapes-employee-motivation 
Moon, M.J. (2000, December). Organizational commitment revisited in new public management: Motivation, organizational culture, sector, and managerial level. Public Performance \& Management Review, 24(2), 177-194. https://doi.org/10.2307/3381267

Newstrom, J., \& Davis, K. (2002). Organizational behavior: Human behavior at work. New York: McGraw Hill.

Robbins, S.P., \& DeCenzo, D.A. (2007). Supervision Today! Upper Saddle River, NJ: Pearson/Prentice Hall.

Sonnenfeld, J.A. (1985, April). Shedding light on the Hawthorne studies. Journal of Occupational Behavior, 6(2), 111-130. https://doi.org/10.1002/job.4030060203

Tracy, B. (2017). Learning leadership: Eight key skills that make an effective manager. Forbes, March 13. Retrieved from

https:/www.forbes.com/sites/forbescoachescouncil/2017/03/13/learning-leadership-eight-key-skills-that-makean-effective-manager/\#2e22bf621354 